\title{
AGING OF NATURAL RUBBER IN AIR AND SEAWATER
}

\author{
P. H. Mott, C. M. Roland* \\ Code 6120, Naval Research Laboratory, Washington DC 20375
}

\begin{abstract}
Accelerated aging experiments were carried out on a natural rubber vulcanizate exposed to air and to seawater. Failure strain, shown to correlate well with the fatigue lifetime, was used to monitor the extent of degradation. The effect of temperature on the rate of aging followed an Arrhenius law, with activation energies equal to $90 \pm 4$ and $63 \pm 3 \mathrm{~kJ} / \mathrm{mol}$ for air and seawater aging, respectively. The difference can be accounted for by the difference in oxygen concentration for the two environments.
\end{abstract}

\section{INTRODUCTION}

To predict the service life of a rubber component subjected to a variety of environments, it is necessary to account for all modes of degradation. This can be difficult in a complex environment such as seawater, where different processes, such as oxidation, swelling, leaching, and even biodegradation, may occur simultaneously. The present study was motivated by the Navy's development of an elastomeric disk as potentially the torpedo launcher on future Virginia-class submarines. ${ }^{1}$ The development of the rubber compound has been described previously. ${ }^{2}$ The disk has a diameter of more than $2 \mathrm{~m}$ and a thickness varying from 20 to $30 \mathrm{~cm}$. It is to be inflated with seawater to $100 \%$ biaxial strain, and the performance must be maintained over roughly 2000 inflation cycles (ca. 15 years). Since any degradation of the mechanical properties will impair a vital function of the submarine, a reliable assessment of longevity is crucial.

An obvious method for lifetime prediction is to accelerate the aging, so that deterioration of properties occurs over a feasible time scale, e.g., a few weeks. The Arrhenius equation ${ }^{3}$ is then used to predict the degradation rate at the service temperature:

$$
\frac{r_{1}}{r_{2}}=A \exp \left[-\frac{E_{a}}{R}\left(\frac{1}{T_{1}}-\frac{1}{T_{2}}\right)\right]
$$

where $r_{1}$ is the reaction rate at temperature $T_{1}$, etc., $A$ is a constant, and $E_{a}$ is the activation energy. Extrapolation of short time, high temperature data in this manner to yield lifetime estimates for rubber exposed to long times at lower temperatures has a long history. ${ }^{4-9}$ Herein, our emphasis is on the material properties that affect the stored energy and the fatigue lifetime, since these directly influence the performance of an elastomeric torpedo launcher.

\section{EXPERIMENTAL}

The rubber formulation is listed in Table I. To insure repeatability, all samples were obtained from a single batch. Test sheets, $120-\times 65-\times 1.5-\mathrm{mm}$, were cured $30 \mathrm{~min}$ at $160^{\circ} \mathrm{C}$, followed by exposure to the various aging environments. Air degradation was carried out in a convection oven (Delta 9023). Seawater aging was performed in vented, enclosed tanks, equipped with temperature controllers and circulators. The brine was prepared by dissolving a commercial preparation (Aquarium Systems Instant Ocean ${ }^{\circledR}$ ) into distilled water, at a concentration of 3.5\%, as determined from

*Corresponding author. Tel: 202-767-1719; fax: 202-767-0594; e-mail: mike.roland@nrl.navy.mil 
TABLE I

RUBBER COMPOUND

\begin{tabular}{|c|c|c|c|}
\hline Ingredient & Trade Name & Source & $\mathrm{phr}$ \\
\hline Deproteinized NR & DP-CV & H.A. Astlett Co. & 100 \\
\hline Zinc oxide & Zinc oxide RG-MA & Akrochem Corp. & 3.0 \\
\hline Zinc di-2-ethylhexoate & Octate Z & R. T. Vanderbilt Co. & 1.5 \\
\hline Diphenylamine-acetone & AgeRite ${ }^{\circledR}$ Superflex Solid G & R. T. Vanderbilt Co. & 1 \\
\hline Zinc 2-mercaptotoluimidazole & Vanox ${ }^{\circledR}$ ZMTI & R. T. Vanderbilt Co. & 0.5 \\
\hline$n$ - $t$-Butyl-2-benzothiazolesulfenimide & Santocure ${ }^{\circledR}$ TBSI & Monsanto Chemical Co. & 1.0 \\
\hline Sulfur & Sulfur RM & Akrochem Corp. & 2.5 \\
\hline Processing aid & Vanfre ${ }^{\circledR}$ AP2 & R. T. Vanderbilt Co. & 3.0 \\
\hline$n$-(Cyclohexythoiphthalimide) & Vantard ${ }^{\circledR}$ PVI & R. T. Vanderbilt Co. & 0.5 \\
\hline $\mathrm{NaO}_{3} \mathrm{SS}\left(\mathrm{CH}_{2}\right)_{6} \mathrm{Na}-\mathrm{H}_{2} \mathrm{O}$ & Duralink $^{\circledR}$ HTS & Monsanto Chemical Co. & 2.0 \\
\hline N110 carbon black & Corax ${ }^{\circledR} \mathrm{N} 110$ & Degussa-Hüls Corp. & 10 \\
\hline N550 carbon black & Corax $^{\circledR}$ N550 & Degussa-Hüls Corp. & 40 \\
\hline
\end{tabular}

the density. Dissolved oxygen concentrations were determined by the indigo-carmine method ${ }^{10}$ (ASTM D 888-87) using a commercial test kit (Chemets).

After aging, specimens were cut from the sheets for room-temperature stress-strain measurements (Instron 4206 with Wallace optical extensometer). Cyclic strain energies were measured at a crosshead strain rate of $1.0 \mathrm{~min}^{-1}$, with a maximum extension of 1.0; data from the third cycle was utilized. Elongation to failure was carried out at an extension rate of $7.5 \mathrm{~min}^{-1}$, with a minimum of seven specimens tested for each condition. Fatigue testing employed a modified Monsanto Fatigue

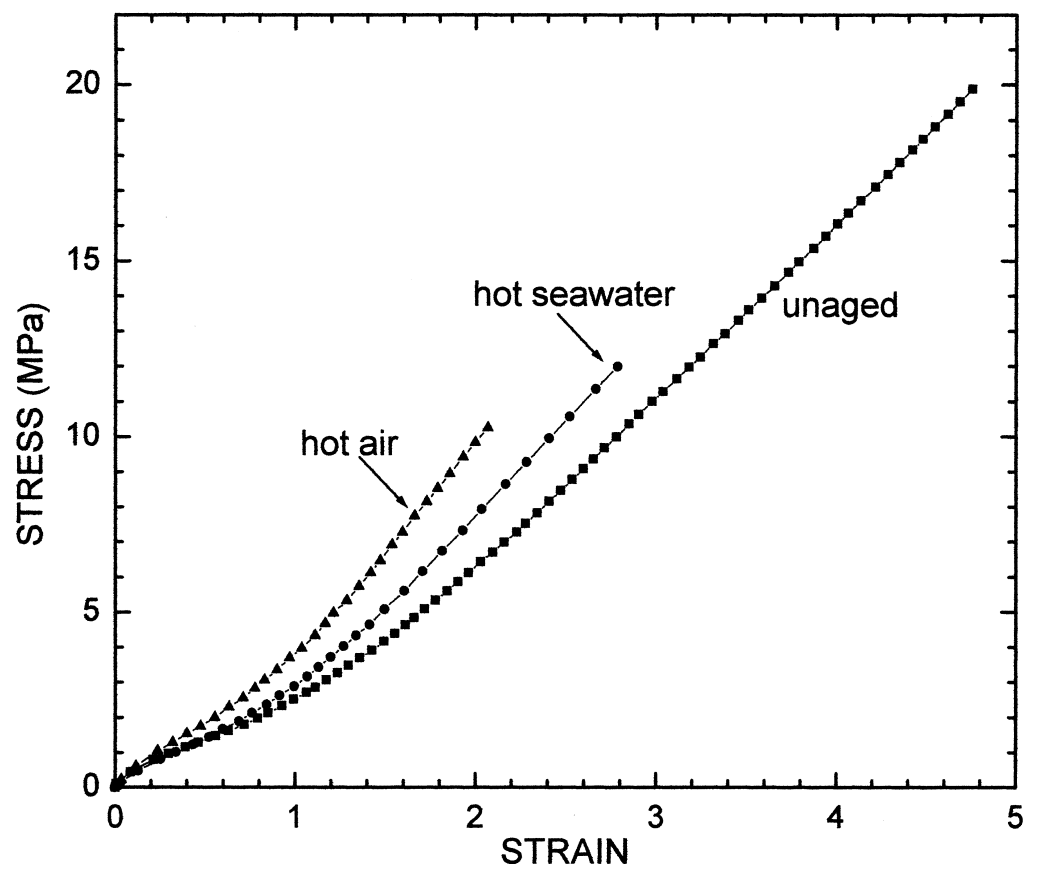

FIG. 1. - Representative elongation to failure curves for the rubber unaged, seawater aged $\left(328.2 \mathrm{~h}\right.$ at $\left.98^{\circ} \mathrm{C}\right)$ and air aged $\left(44.8 \mathrm{~h}\right.$ at $\left.120^{\circ} \mathrm{C}\right)$. 
to Failure apparatus (ASTM D 4482-85), testing 12 samples per exposure condition at an elongation of 1.26 .

Thermogravimetic analysis (TGA) was carried out using a Perkin-Elmer TGA-7 with flowing air.

\section{RESULTS AND DISCUSSION}

\section{ELASTIC PROPERTIES}

Figure 1 illustrates the effect of aging on the stress-strain curve for the rubber. There is a substantial decrease in the failure strain, along with an increase in modulus. Air aging consistently caused the modulus to increase with time at all temperatures, although at the highest aging temperature $\left(120^{\circ} \mathrm{C}\right)$ the increase was no more than $50 \%$. The consequences of seawater aging were less marked, with changes in the stress-strain curve discernible above the experimental scatter only for longer exposure times.

\section{FAILURE PROPERTIES}

The failure properties decline with the extent of aging, as shown in Figure 2 (air exposure) and Figure 3 (seawater exposure). Similarly, the fatigue life, measured after air aging at $110^{\circ} \mathrm{C}$, decreases with aging time (Figure 4).

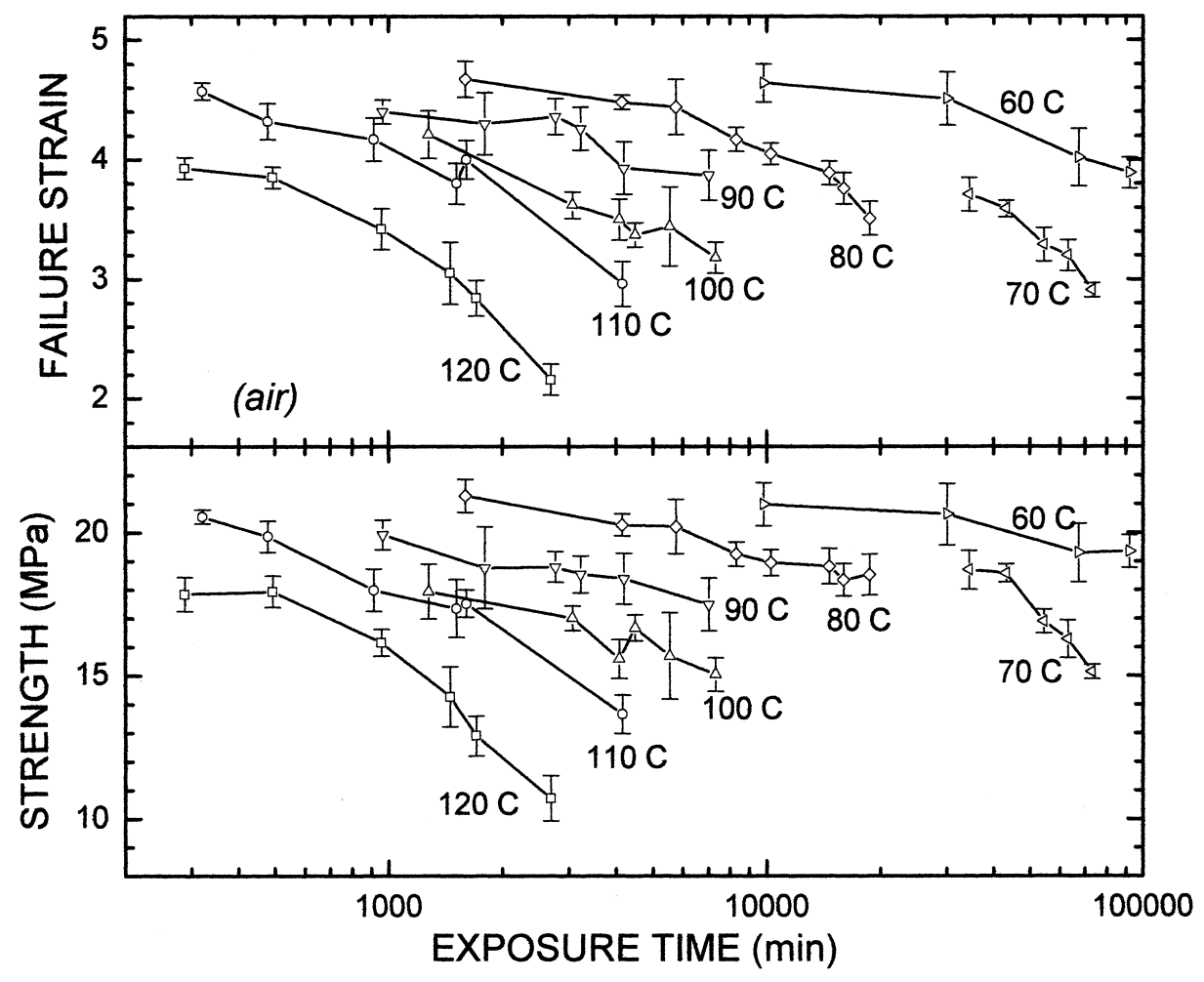

FIG. 2. - Effect of air aging at the indicated temperatures on elongation at break and tensile strength. 


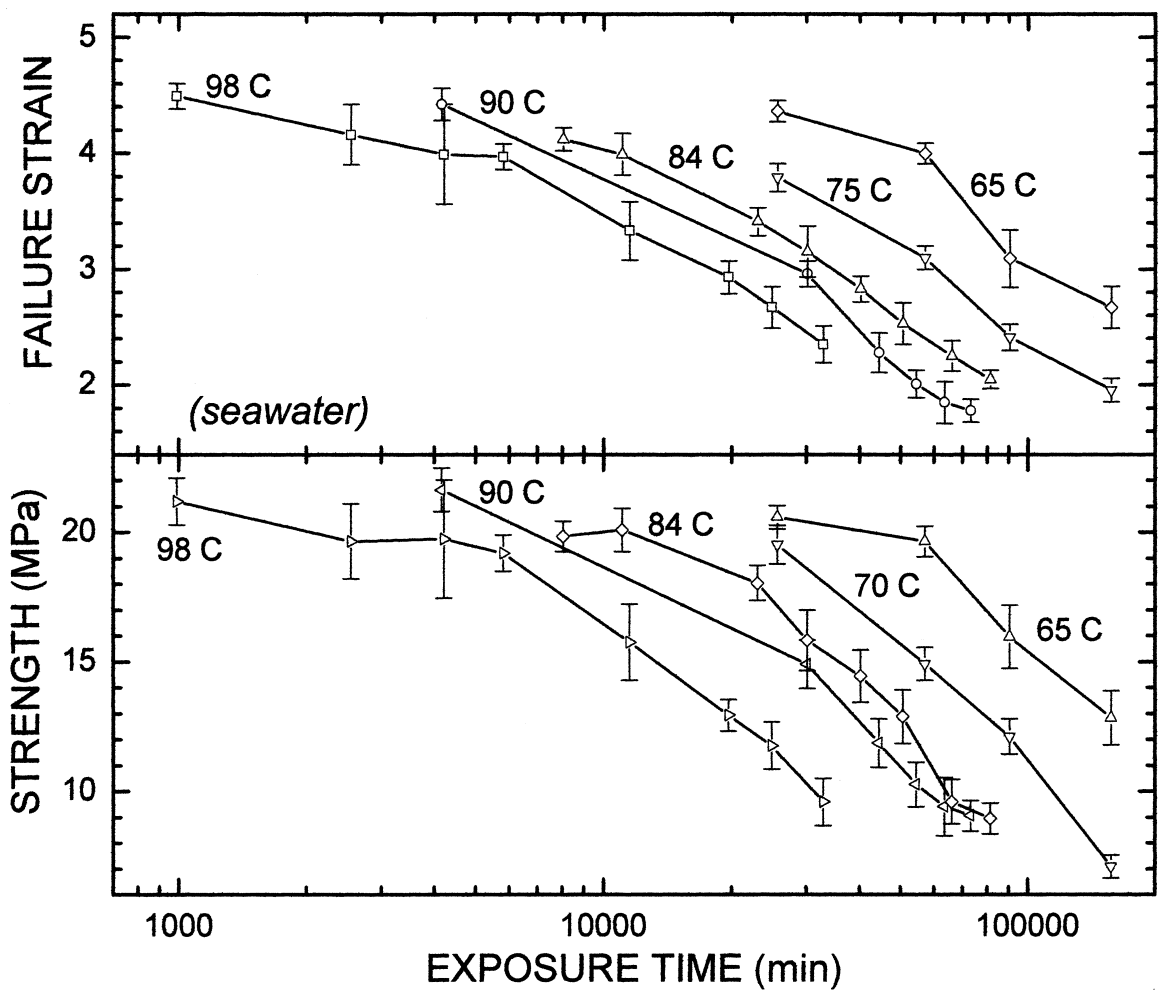

FIG. 3. - Effect of seawater aging at the indicated temperatures on elongation at break and tensile strength.

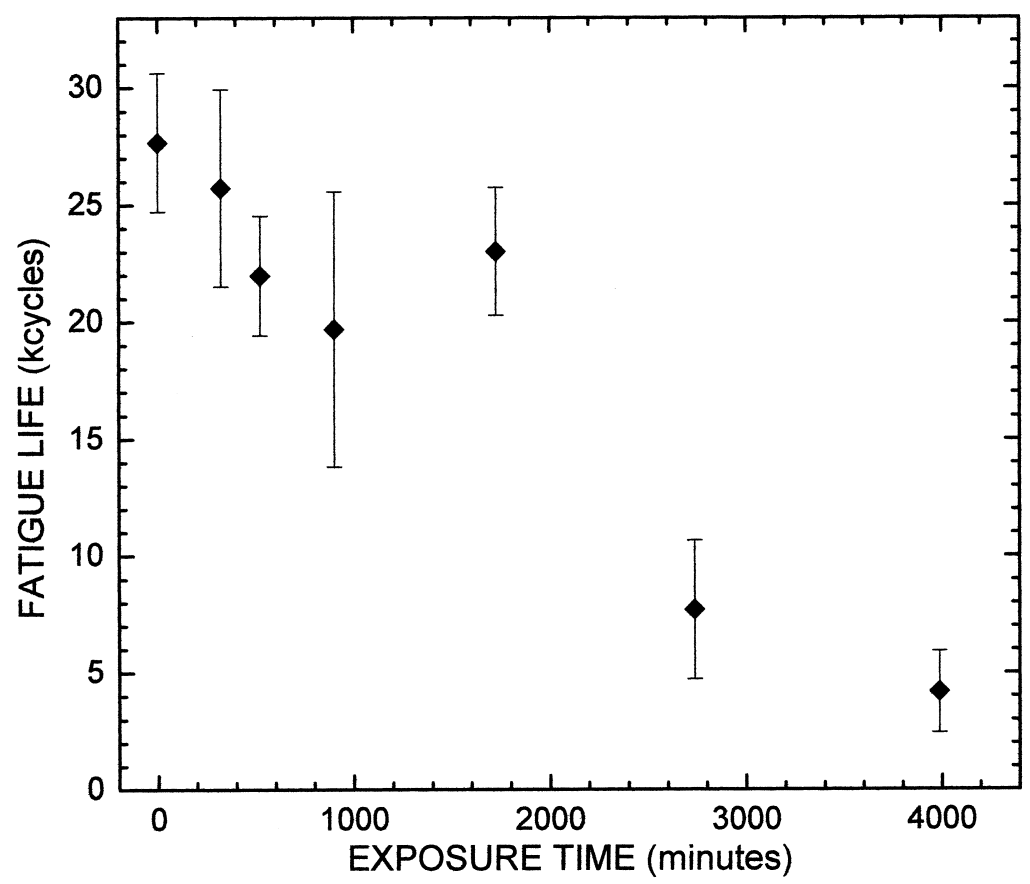

FIG. 4. - Fatigue life after air aging at $110^{\circ} \mathrm{C}$ as a function of exposure time. 
Usually, the failure of rubber in tension is interpreted using fracture mechanics, where the number of cycles, $N$, depends on the strain energy, $W$, as ${ }^{11,12}$

$$
N=\frac{1}{(\beta-1) B(2 K W)^{\beta} c_{0}^{\beta-1}}
$$

in which $c_{0}$ is the intrinsic flaw size, and $B$ and $\beta$ are material constants. The parameter $K$ is a slowly varying function of $\operatorname{strain}^{13}$

$$
K=\frac{\pi}{\sqrt{\lambda}}
$$

where $\lambda$ is the stretch ratio.

Equation (2) can be used to relate the tensile fatigue life to the breaking strain for a given material, but aging induces chemical changes. The cut growth properties (i.e., $B$ and $\beta$ ), and also the strain energy for a given $\lambda$ change with aging. Nevertheless, the fatigue life of aged samples correlates well with their failure strain (Figure 5). This means that we can use Equation (2) to relate failure strain to fatigue life.

In Figure 6 is shown a double logarithmic plot of the fatigue life as a function of the ratio of the strain energy parameter, $K W$ in Equation (2), for $N=1$ (single extension to break) to that for fatigue testing at $\lambda=2.26$; the exponent is 1.6. Note that if the changes in fatigue life were due only to changes in strain energy (i.e., the material per se were unchanged), the slope of Figure 6 would correspond to the $\beta$ in Equation (2). For unfilled natural rubber $(\mathrm{NR}), \beta \approx 2 .{ }^{14,15}$ The relationship in Figure 6 is nearly quadratic, with at least some of the difference reflecting the changes in the material itself.

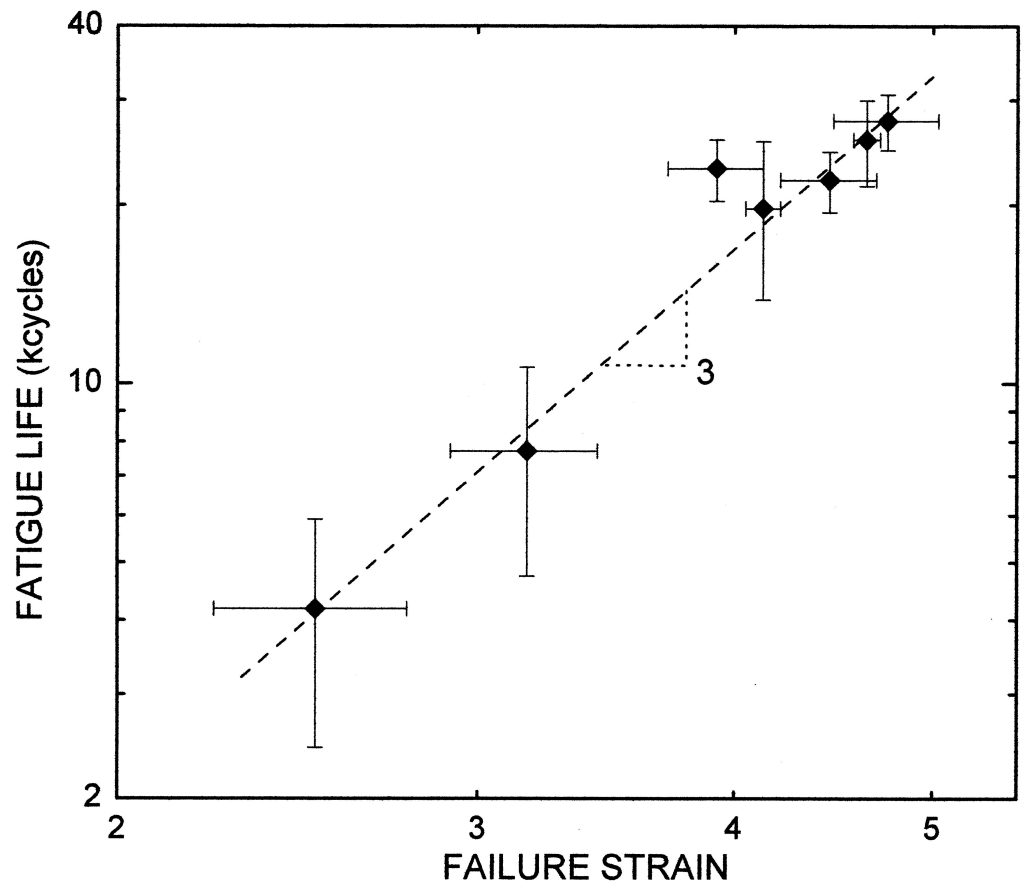

FIG. 5. - Correlation of the fatigue life versus the elongation at break for air aging at $110^{\circ} \mathrm{C}$. Note the scales are both logarithmic. 


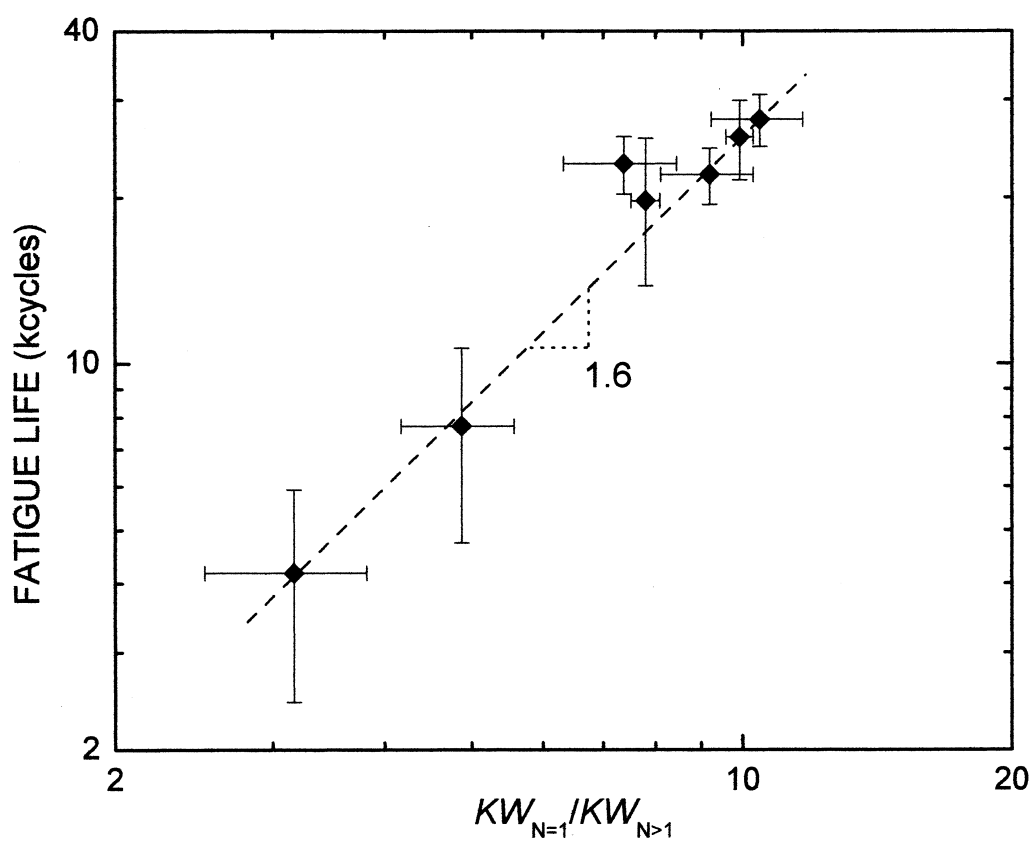

FIG. 6. - Fatigue life versus the reciprocal of the strain energy parameter, normalized by the strain energy for a single elongation to break.

TEMPERATURE DEPENDENCE OF AGING

The parallel curves for the failure strain in Figures 2 and 3 imply that a single aging mechanism dominates over these temperatures. In Figure 7 are master curves for aging in air and in seawater,

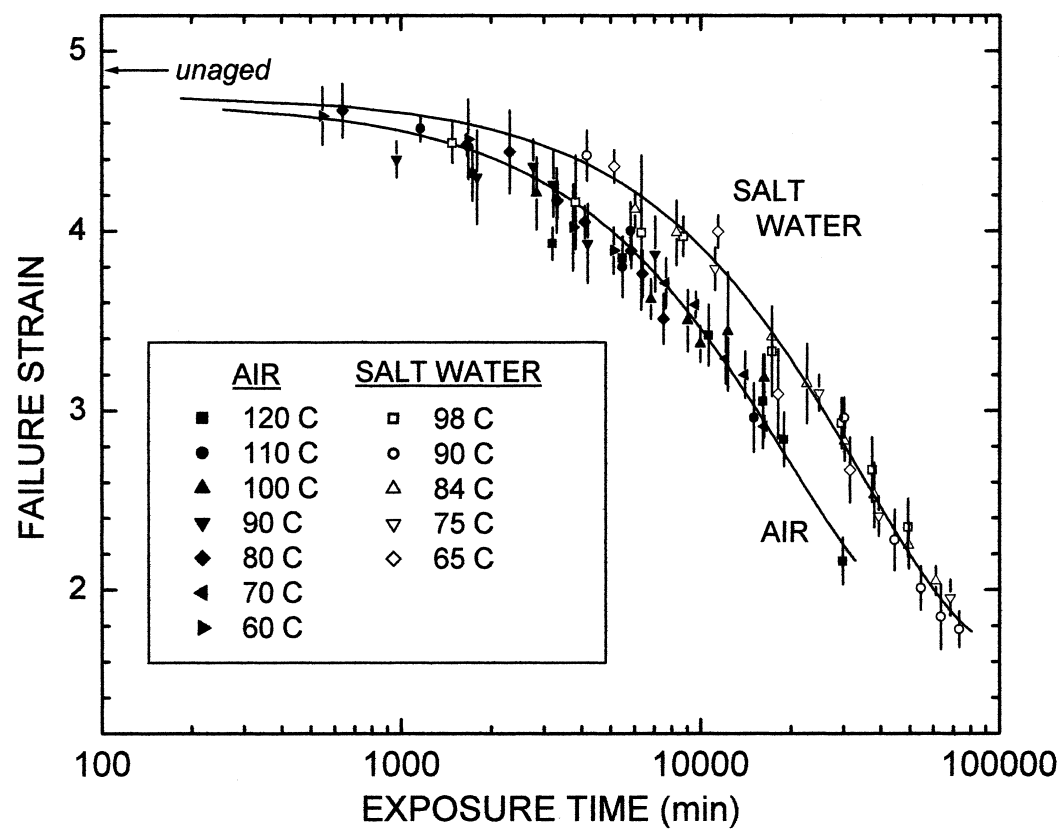

FIG. 7. - Superpositioned "master" aging curves for air and seawater, at a reference temperature of $90^{\circ} \mathrm{C}$. 
constructed by shifting the data along the time axis, using a reference temperature of $90^{\circ} \mathrm{C}$. The two master curves are also parallel, again suggesting that the underlying degradation chemistry is the same.

The shift factors used to construct Figure 7 are displayed in Figure 8 in the Arrhenius form, yielding $E_{a}=90 \pm 4 \mathrm{~kJ} / \mathrm{mol}$ and $63 \pm 3 \mathrm{~kJ} / \mathrm{mol}$ for air and seawater, respectively. This activation energy for air aging agrees with literature values for NR compounds obtained by various methods, viz. $88 \leq E_{a} \leq 98 \mathrm{~kJ} / \mathrm{mol}{ }^{16-18}$ Analyses based on puncture energy ${ }^{19}$ and surface chemistry ${ }^{20}$ yield somewhat lower values, ca. $75-80 \mathrm{~kJ} / \mathrm{mol}$.

\section{OXYGEN SOLUBILITY}

Although the aging curves in Figure 7 for the two environments are parallel, the activation energy for seawater is significantly lower than for air. Thus, while the chemical mechanism of rubber degradation may be the same, it is apparent that some other factor exerts an influence. The obvious difference between the two media is the availability of oxygen. It is well known that the solubility of oxygen in water decreases with temperature. This solubility is expressed by Henry's law $^{21}$

$$
x_{\mathrm{O}_{2}}=\frac{P_{\mathrm{O}_{2}}}{k}
$$

in which $x_{\mathrm{O}_{2}}$ is the mole fraction of dissolved oxygen, $P_{\mathrm{O}_{2}}$ the partial pressure, and $k$ a constant. The temperature dependence of $k$ contributes to the difference in aging behavior for rubber in air versus seawater. Published data for various brine solutions ${ }^{22,23}$ can be interpolated to obtain a value of $k$ for seawater. The partial pressure of oxygen in seawater also varies with temperature, because

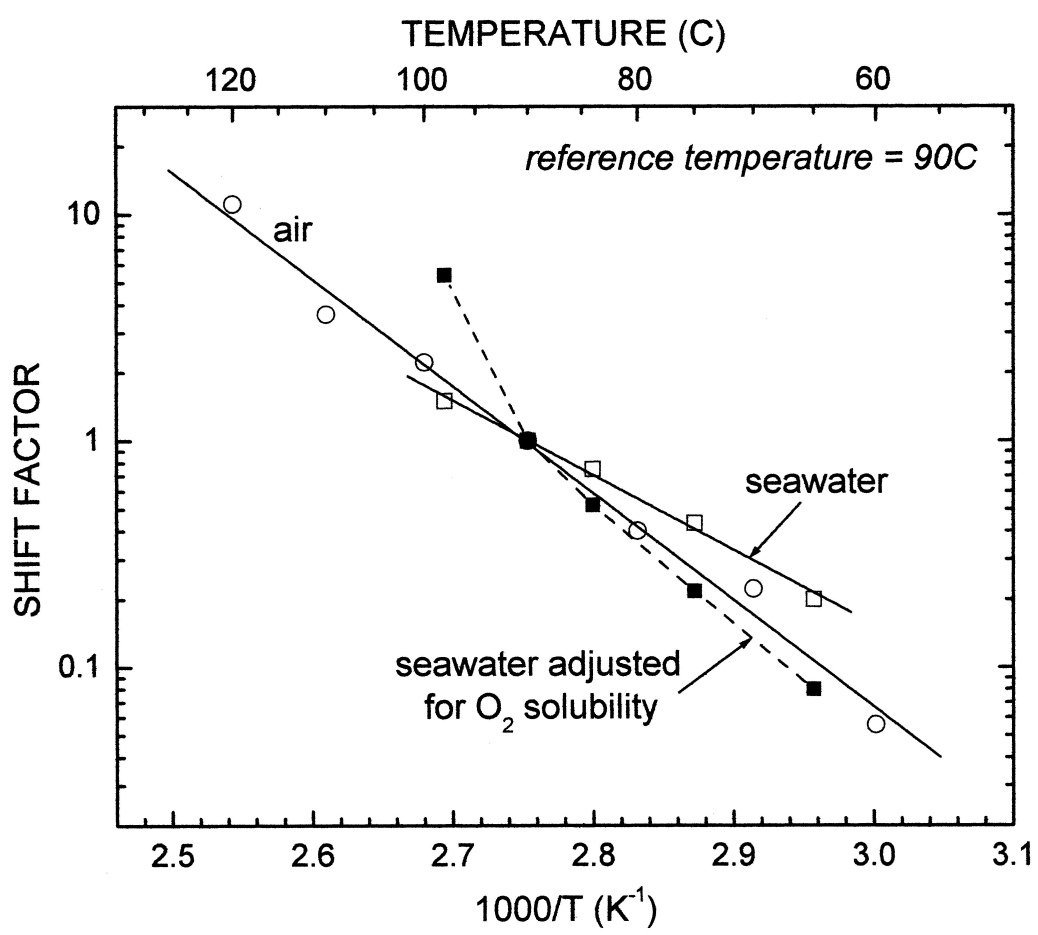

FIG. 8. - Horizontal shift factors used to construct the master curves in Figure 7. The slopes yield $E_{a}=90$ and 63 $\mathrm{kJ} / \mathrm{mol}$ for air and seawater aging, respectively. The dashed curve represents the data for seawater after factoring out the temperature dependence of oxygen solubility. 
in a closed vessel, it is being displaced. To estimate $P_{\mathrm{O}_{2}}$ in our tank, the contribution of the water vapor pressure, $P_{\mathrm{H}_{2} \mathrm{O}}$, must be taken into account. Since air consists of $21 \% \mathrm{O}_{2}$,

$$
P_{\mathrm{O}_{2}}=0.21 \frac{P_{\mathrm{T}}-P_{\mathrm{H}_{2} \mathrm{O}}}{P_{\mathrm{T}}}
$$

where the total pressure, $P_{\mathrm{T}}$, is $101 \mathrm{kPa}$. Equation (5) indicates that as the temperature approaches the boiling point, water vapor will displace the air in a closed system. Under these conditions, the oxygen partial pressure approaches zero and thus the dissolved oxygen becomes negligible. Of course, this is only approximately achieved in the present case.

Values of $P_{\mathrm{H}_{2} \mathrm{O}}$ for salt water were extracted from published data ${ }^{24}$ by interpolation, with the temperature shifted by the boiling point elevation, $\Delta T_{\mathrm{B}}$, due to the dissolved salt ${ }^{25}$

$$
\Delta T_{\mathrm{B}}=0.52 \mu
$$

where the ionic strength of the seawater, $\mu$, is 0.7 . The computed values of $x_{\mathrm{O}_{2}}$ are displayed in Figure 9, along with measured concentration of dissolved oxygen. It can be seen in the figure that the agreement is quite good, excepting the highest temperature, at which the calculation underestimates the measured value.

To account for the effect of oxygen solubility on the rubber's aging, the shift factors for seawater were multiplied by the oxygen solubility at each temperature, normalized by the solubility at the reference temperature, $90^{\circ} \mathrm{C}$. As shown in Figure 8 (dashed line), the shift factors for seawater are nearly equivalent to those for air. The only exception is at the highest temperature $\left(98^{\circ} \mathrm{C}\right)$, where the measurement diverges from theory. It is evident that the temperature dependence of oxygen solubility is largely responsible for the difference between the activation energies for air and seawater.

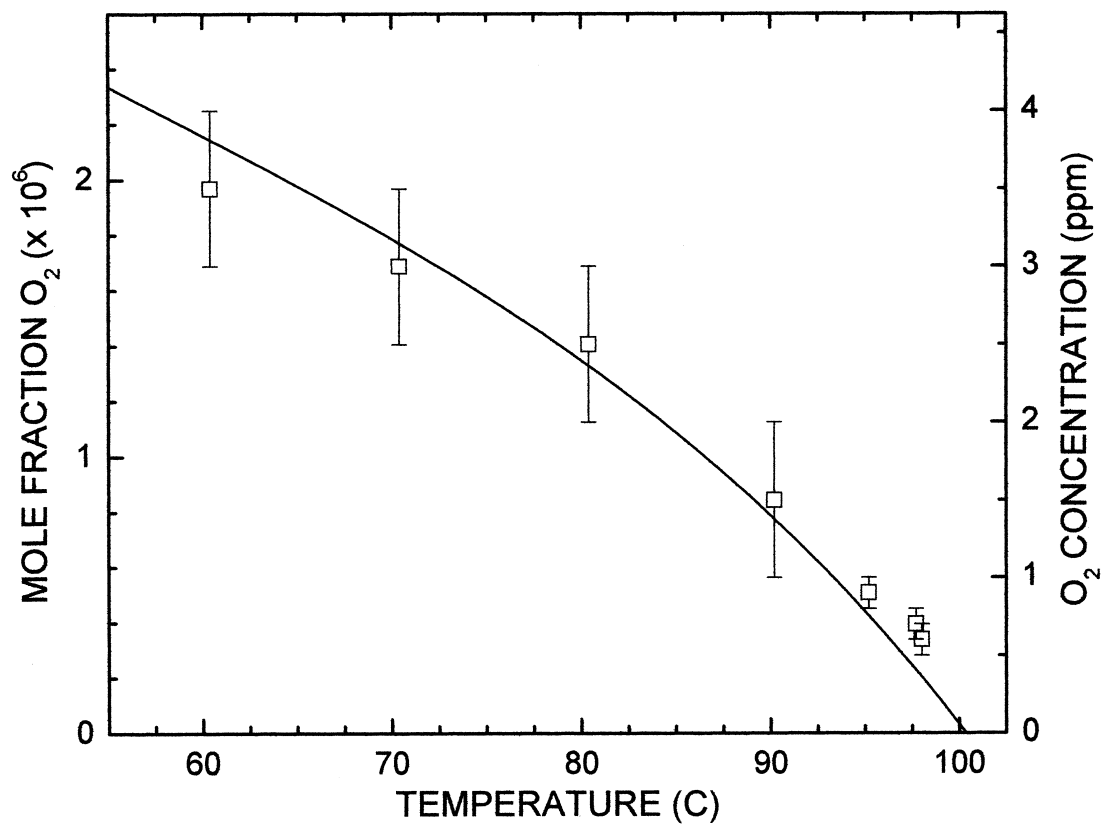

FIG. 9. - Oxygen solubility measured for seawater ( $\square$ ), along with the calculated values (solid line) from Equations (4), (5), and (6) using literature values for $k$ (see text for details). The ordinate scale is mole fraction on the left and weight per weight on the right. 


\section{THERMAL GRAVIMETRIC ANALYSIS}

Thermal analysis techniques can be used to quickly obtain $E_{a}$ from the dependence of the decomposition temperature on heating rate. ${ }^{26-30}$ TGA was carried out on the present compound; however, significant degradation only transpired at temperatures exceeding $325^{\circ} \mathrm{C}$. According to Figure 7, a loss of properties becomes significant after about $10,000 \mathrm{~min}$ at $90^{\circ} \mathrm{C}$. Using the activation energy determined for air, $E_{a}=90 \mathrm{~kJ} / \mathrm{mol}$, we calculate that an equivalent degree of degradation would require only a few seconds at a temperature as high as $325^{\circ} \mathrm{C}$. This is much less than the time it takes to reach this temperature at a typical TGA scan rate. This means that the degradation observed by TGA involves quite different processes (e.g., volatilization of small molecule fragments, formation of amorphous carbon, etc.) than the oxidation of the unsaturated backbone of the polyisoprene responsible for the loss of failure properties of interest herein. Thus, notwithstanding the convenience of thermal analysis techniques, inferences drawn from such experiments are likely to be misleading with regard to typical service lifetimes.

\section{AMBIENT AGING}

It would be of interest to compare the predictions of the accelerated aging experiments to aging at actual service temperatures. Attempting to do so, however, emphasizes the need for accelerated aging; that is, deterioration involves very extended time periods at room temperature. The remarkable longevity of natural rubber compounds has been noted in the literature, ${ }^{19,31}$ including in seawater. ${ }^{32}$ Nevertheless, samples of the present material were annealed at room temperature in air for 653 days. The properties of these specimens, failure strain $=4.92 \pm 0.08$ and tensile strength $=21.8 \pm 0.5 \mathrm{MPa}$, were identical to that of unaged samples.

Taking the laboratory temperature to be $20^{\circ} \mathrm{C}$, and using Equation (1) with $E_{a}=90 \pm 4 \mathrm{~kJ} / \mathrm{mol}$, 653 days at ambient temperature corresponds to $760 \pm 240 \mathrm{~min}$ at $90^{\circ} \mathrm{C}$. From the curve in Figure 7 , the failure strain is predicted to be $4.63 \pm 0.15$, slightly lower than the measured value. The curve in Figure 7 is relatively flat over the first 1000 min; thus, almost 2 years of ambient temperature aging is insufficient to cause substantial changes in properties. Presumably antioxidant depletion is incomplete, so that the failure properties are maintained. The error associated with measurement of failure properties governs the accuracy of the prediction.

\section{CONCLUSIONS}

Accelerated aging experiments can provide useful estimates of service lifetimes in complex environments, provided consideration is given to all contributing processes. Of course, confidence in such estimates is reinforced by corroboration with aging under actual service conditions. However, for a well-formulated natural rubber compound such as herein, only the initial part of the degradation curve could be verified. A severe deterioration of properties requires impracticably long time periods.

The underlying assumption of this study has been that environmental aging of the rubber is primarily due to oxidation. Accounting for the temperature dependence of oxygen solubility in seawater supports this assumption, and allows the different temperature dependences of air and seawater aging to be reconciled. It is also noteworthy that the test specimens herein were two orders of magnitude thinner than the elastomeric disk intended to serve as a torpedo launcher. To the extent that degradation is limited to the surface, even severe deterioration of laboratory samples would not imply failure of a full-sized disk. It has been found that a highly oxidized layer can develop on the surface of rubber, with this "skin" functioning as a protective barrier for the sample bulk. ${ }^{19,33}$ Similarly, bacterial attack, which is known to degrade natural rubber, ${ }^{34}$ is primarily a surface phenomena, and hence not relevant herein.

Finally, we point out that fluid absorption and leaching can influence the performance of rubber exposed to liquid media. However, the equilibrium uptake of seawater by sulfur-cured, deproteinized 
natural rubber has reported to be only $1 \%$ by weight. ${ }^{35}$ Moreover, measurements of the diffusion constant for water in the present compound at room temperature yield a value of $4.0 \times 10^{-12} \mathrm{~m}^{2} / \mathrm{s}$. This corresponds to permeation of only $6 \mathrm{~cm}$ after fifteen years immersion in seawater.

\section{ACKNOWLEDGMENTS}

This work was supported by the Naval Undersea Warfare Center.

\section{REFERENCES}

${ }^{1}$ J. Little, Undersea Warfare 1(3), 12 (1999).

${ }^{2}$ I. S. Choi, C. M. Roland, and L. C. Bissonnette, Rubber Chem. Technol. 67, 892 (1994).

${ }^{3}$ S. Arrhenius, Z. Phys. Chem. 4, 226 (1889); 31, 197 (1899).

${ }^{4}$ J. A. Kuczkowski and D. E. Miller, Ed. Symp. no. 23, paper no. F, presented at the fall meeting of the Rubber Division, American Chemical Society, Detroit, MI, Detroit, MI, 1989.

${ }^{5}$ K. Hashimoto and Y. Todani in "Handbook of Elastomers," A. K. Bhowmick and H. L. Stephens, Eds., Marcel Dekker, New York, 1988, Chapter 24.

${ }^{6}$ L. A. Wall and J. H. Flynn, Rubber Chem. Technol. 35, 1157 (1962).

${ }^{7}$ R. Brown, "Physical Testing of Rubber," 3rd ed., Chapman \& Hall, London, 1996.

${ }^{8}$ L. A. Goettler, A. J. Lambright, R. I. Leib, and P. J. DiMauro, Rubber Chem. Technol. 54, 277 (1981).

${ }^{9}$ K. T. Gillen, M. Celina, R. L. Clough, and J. Wise, Trends Polym. Sci. 5, 250 (1997).

${ }^{10}$ T. W. Gilbert, T. D. Behymer, and H. B. Castaneda, Amer. Lab. 14, 119 (1982).

${ }^{11}$ R. S. Rivlin and A. G. Thomas, J. Polym. Sci. 10, 291 (1953).

${ }^{12}$ G. J. Lake, Rubber Chem. Technol. 68, 435 (1995).

${ }^{13}$ P. B. Lindley, J. Strain Anal. 7, 132 (1972).

${ }^{14}$ A. G. Thomas, J. Polym. Sci. 31, 467 (1958).

15 A. N. Gent, P. B. Lindley, and A. G. Thomas, J. Appl. Polym. Sci. 8, 455 (1964).

${ }^{16}$ A. V. Tobolsky and A. Mercurio, J. Amer. Chem. Soc. 81, 5535 (1950).

${ }^{17}$ R. W. Keller and H. L. Stephens, Rubber Chem. Technol. 55, 161 (1982).

${ }^{18}$ V. Kello, A. Tkac, and J. Hrivikova, Rubber Chem. Technol. 29, 1245 (1956); 1255 (1956).

${ }^{19}$ K. A. Malek and A. Stevenson, J. Nat. Rubber Res. 7, 126 (1992).

${ }^{20}$ P. B. Lindley and S. C. Teo, Plast., Rubber Matl. Appl. 2, 152 (1977).

${ }^{21}$ A. W. Adamson, “A Textbook of Physical Chemistry," 2nd ed., New York, Academic Press, 1979, Chapter 9.

${ }^{22}$ S. D. Cramer, Ind. Eng. Chem. Process Des. Dev. 19, 300 (1980); 23, 618 (1984).

${ }^{23}$ A. H. Harvey, AIChE J. 42, 1491 (1996).

${ }^{24}$ A. Saul and W. Wagner, J. Phys. Chem. Ref. Data 16, 893 (1987).

${ }^{25}$ W. L. Masterton and E. J. Slowinski, "Chemical Principles" 4th ed., W B Saunders, Philadelphia, 1977, Chapter 13.

${ }^{26}$ A. K. Sircar, in "Thermal Characterization of Polymeric Materials," E. A. Turi, Ed., 2nd ed., Academic Press, New York, 1997, Vol. 1, p. 888.

${ }^{27}$ G. Jander and C. Bloom, Z. Anorg. Chem. 258, 205 (1949).

${ }^{28}$ M. A. Ponce-Velez and E. Campos Lopez, J. Appl. Polym. Sci. 22, 2485 (1978).

${ }^{29}$ H. E. Kissinger, J. Res. Natl. Bur. Stand. (U.S.) 57, 217 (1956).

${ }^{30}$ T. Ozawa, J. Therm. Anal. 2, 301 (1970).

${ }^{31}$ B. J. Davies, Rubber Dev. 41(4), 102 (1988).

${ }^{32}$ K. Ab-Malek and A. Stevenson, J. Mater. Sci. 21, 147 (1986).

${ }^{33}$ F. Björk and B. Stenberg, Polym. Testing 5, 245 (1985).

${ }^{34}$ Anon., Rubber Dev. 43(1/2), 19 (1990).

${ }^{35}$ K. N. G. Fuller, M. J. Gregory, J. A. Harris, A. H. Muhr, A. D. Roberts, and A. Stevenson in "Natural Rubber Science and Technology,” A. D. Roberts, Ed., Oxford University Press, Oxford, 1988, Chapter 19. 